\title{
Promoting Multilingualism in the Classroom: A Case Study of ELT Program
}

\author{
Muhammad Nafi Annury \\ UIN Walisongo Semarang \\ nafiannury@gmail.com
}

\begin{abstract}
The article gives a brief analytical survey of multilingualism practices, its consequences, and its benefits in education and discussions on the appropriate ways towards its achievement in education. Multilingualism refers to speaking more than one language competently. Generally, there are both the official and unofficial multilingualism practices. This study was descriptive qualitative. The subjects of the study were eighty students and divided into two classes. Purposive sampling technique was applied in identifying students who tended to practice multilingualism in education in EFL class. The benefits of multilingualism practices in education were realized by relying on text analysis of the written materials on education and psychology. Personal experience in educational matters especially the educational processes in EFL class is also included. Findings were descriptively presented in continuous prose. Students still had problems on the way they speak and write in English well. However, there were only $1.9 \%$ students who felt that they influenced in speaking and even writing English well. It is quite a challenging issue towards students implementing multilingualism within the classroom. Even though, they are already learned English since they were from junior high school, fortunately.
\end{abstract}

ARTICLE HISTORY

Received 22 April 2017

Accepted24 April 2017

\section{KEYWORDS}

Multilingualism; classroom;

ELT; case study

\section{Introduction}

Indonesian is societal multicultural marriages forms of cultural difference among different languages. Besides the diversity in the dialect which is owned by Indonesianas the national language, the needs for foreign language abolish proficiency especially English strengthen the status of Indonesians into social multilingual. Many languages in large cities, used various by various people, therefore, make contact their language and culture inevitable. The language used like this situation may, of course, has the potential to cause rivalry or conflicts (in dialect, national, and foreign languages) and then not observed and anticipated, however, can take social disharmony for survival language especially for vernacular, so that it would need proper planning as well.

Humans need an organized medium of communication in any given social set up. This medium is generally referred to as language. Though it appears challenging to define the term language due to its social complexity clearly, it is generally agreed 
amongst scientific intelligentsia that it is a system of symbols designed for communication. This system involves a collection of entities organized into a whole and arranged in such a way that they work together to achieve a particular function (Lyon, 1981). Language as a medium of communication amongst humans possesses numerous attributes such as being governed by rules, is a system and performs such functions as giving information, expressing feelings and emotions, establishing rapport, exercising authority and an identity marker (Webb, 2000). As humans use more than one language then terminologies such as bilingualism, trilingualism, and multilingualism arise.

The term multilingualism which is the focus of this article is derived from two Latin words namely "multi" that means many and "lingua" that means a language (Bussmann, 1996). Thus multilingualism is referred to as the ability of a speaker to express himself or herself in several languages with equal and native-like proficiency (Bussmann, 1996). However, it has been realized in both the written and verbal communicative practices that proficiency in one language usually tends to dominate in a multilingual set. Multilingualism can also be regarded as the co-existence of several languages within a society (Lyon, 1981). These several languages can be official or unofficial, native or foreign and national or international.

Sometimes multilingualism is used interchangeably with bilingualism (Lyon, 1981) that refers to the ability to speak two languages with native-like proficiency. Multilingualism is considered in this article as an inclusive terminology comprising bilingualism (ability to speak two languages proficiently), trilingualism (ability to speak three languages) and there are also instances whereby one speaker can speak even more than three languages. Since the prefix 'multi' refers to more than one, both bilingualism and trilingualism will therefore technically refer to more than one language. As we use several languages, we become multilingual.

Any given country or society is generally considered as a multilingual one if its members or citizens are multilingual. The multilingual citizens on many occasions tend to show the identifiable full range of communicative competence in several languages in place. However, there is rarely perfect multilingualism in practice. The rare perfect practice occurs because even if we acquire both or several languages in place, there is always a notable tendency that one language will always dominate over the others which are considered subordinates.

The tendency that shows a clear functional differentiation of two languages is generally referred to as diglossia. In this case, one language regarded as a low variety (L) may be used at home or informal environments and the other regarded as a high variety $(\mathrm{H})$ is used in specialized formal functions. There are also instances whereby functional differentiation of three languages is involved. This tendency generally gives rise to triglossia. A glimpse of triglossia can be witnessed in Indonesia whereby English is regarded as a high variety used as the sole medium of instruction of all disciplines taught in various schools and higher learning institutions. About 
forty indigenous languages are spoken at homes and other social places. It is evident that none of the indigenous languages is used as a medium of instruction of disciplines in any of the learning institutions in Indonesia.

In general, the functional differentiation of languages tends to give rise to other ways of classifying languages as mother tongue (the first language of a speaker), vernacular (the language spoken in a particular area or specific group of people but not generally an official), national, official and the global or international languages.

This research was conducted to answer the following questions: (1) How is the students' response about using multilingualism in the classroom?; (2) What problems are revealed in implementing multilingualism in the classroom?; (3) What is the benefit of implementing multilingualism in the classroom?

\section{Background literature}

\section{Language concept}

The identity of any human society is a well-developed language. The ideological stance of the sentences regarding the maintenance of heritage language and culture is made explicit in two dialogues that reflect a meta-discourse as well.

Greenberg (1971: 156) says: "Language is unique to man. No other species possesses a truly symbolic" - means of communication and no human society, however pure its material. In a multilingual sign, for example, the dominant or more prestigious language will often be in larger font. In a multilingual sign, for example, the dominant or more prestigious language will often be in larger font.

Noam Chomsky defines language, as a particular set of sentences that can be generated from a particular set of rules. From above assertions, it is evident that language is an important feature that distinguishes man from other creatures. Also, language and society go hand in hand. Language can be seen as a medium of communication, among people of the same cultural background and beyond.

Language can serve other functions, apart from being a medium of communication. Haliday (1980:20) has the opinion that understanding the nature and functions of language are key elements in learning about language. Haliday (1973) identified 7 functions which includes textual, ideational functions. Brynato (1983) identified transactional and interactional functions. Hyme (1992) identified emotive, poetic functions crystal (1997) identified eight functions, including language as an instrument of thought. The use of language in society has contributed immensely to the socialization process in human society.

\section{Multilingualism and language contact}

Multilingualism is a societal phenomenon that deals with languages existing in a society. When many languages exist in a society, such society is said to be 
multilingual. A person who is proficient in many languages is referred to as a multilingual. Appel and Muysken (1987: 2-5), states the fact that varieties of the same language, maybe in used, in a given situation. The idea of language contact transcends dialectal frontiers. It is an issue which concerns two or more district and independent languages. It is evident that language contact is a situation that concerns two or more languages, co-existing in a particular society. Language contact phenomena result in some phenomena, such as code mixing, code-switching, language shift, language loss, interference, transfer.

\section{Methods}

The paper relied on a survey design whereby classroom practicing multilingualism in general communication and or educational functions were surveyed in the second semester of English department of FITK UIN Walisongo Semarang in the academic year of 2015/2016. There were eighty students and divided into two classes. The article is qualitative research. Purposive sampling technique was applied in identifying students who tend to practice multilingualism in education in EFL class. Benefits of multilingualism practices in education were realized by relying on text analysis of the written materials on education and psychology. Personal experience in educational matters especially the educational processes in EFL class is also included. Findings are descriptively presented in continuous prose.

The data were collected with permission from lecturers and students in English classes. The questionnaires were distributed to students enrolled in English courses. The researcher provided instructions on how to complete the questionnaire. To obtain the reliability of the data, this group of participants was informed that there was no right or wrong answer, and the questionnaire was only for the research purposes. The data obtained from the questionnaires were coded and statistically analyzed to establish frequency distribution in the form of descriptive statistics. Likert scale used to know students' response to promoting multilingualism in the classroom.

\section{Findings}

\section{Multilingualism in the Classroom}

This section presents the results of the descriptive statistics. Generally, some of the responses received rendered significant results, while some others did not. This section is structured into four broad thematic areas: firstly, the general survey of multilingualism practices in the EFL classrooms. Secondly, explanations of the farreaching consequences of multilingualism practices. Thirdly, discussions on significant benefits of multilingualism practices in the educational circles. Probably the most exciting results, at least for our purposes, are those relating to proficiency 
in English. Questions 6a and $6 \mathrm{~b}$ of the questionnaire asked respondents to rate their abilities in speaking English.

Table 1.1975 Survey Reports of Ability to Speak English

Questions 6 (a) and 6 (b): How well do you speak (and write) English?

\begin{tabular}{lll}
\hline & \multicolumn{2}{l}{ Skill (Percentage Ratings) } \\
\hline Response & Speaking & Writing \\
\hline Not at all & $45.2 \%$ & $46.2 \%$ \\
\hline Only a little & $22.1 \%$ & $19.9 \%$ \\
\hline Enough to communicate simple needs & $22.5 \%$ & $23.0 \%$ \\
\hline Enough to communicate a wide range of ideas & $8.3 \%$ & $9.0 \%$ \\
\hline Almost like a native & $1.9 \%$ & $1.9 \%$ \\
\hline
\end{tabular}

From the above table 1 we can thus conclude that at least $32.7 \%$ of the respondents reported an ability in speaking English that went beyond 'only a little' 1 thus responding positively to the three 'higher' categories: 'Enough to communicate simple needs', 'Enough to communicate a wide range of ideas', and' Almost like a native' 1 categories that broadly correspond to an 'adequate', 'good', and 'excellent' rating of one's own ability in speaking - the language. Similarly, we can observe that $33.9 \%$ of the sample indicate a similar level of proficiency in the written language. The survey report (British Council 1979) then goes on 1 language use for specific purposes, English outside work, reasons for studying English, and language attitudes.

Based on the table above it is seen that there $45.2 \%$ of students still have the problem on the way how to speak and how to write in English well. However, there are only $1.9 \%$ of students who feel that they fluence in speaking and even writing English well. It is quite a challenging issue towards students implementing multilingualism within the classroom. Even though, they are already learned English since they were from junior high school, fortunately.

Though there is the vernacular and official language in Indonesia, English is predominantly introduced through formal schooling. Most of the students still use their vernacular within the classroom. Lectures often seem to use Indonesian and English for strengthening their ideas in delivering their subject matters. This condition is common; therefore, students have to explore their competency more during studying in this faculty. Lecturers should encourage students to lots of things in penetrating academic atmosphere comprehensively within or outside of the campus.

The consequences of multilingualism are numerous ranging from linguistic and socio-political. Linguistic consequences of multilingualism include among others the creation and growth of lingua franca that usually develops because of the need for 
cross-group communication (Webb, 2000). Multilingualism practice creates the development of mixed languages mainly due to intense language contact. As result speakers, therefore, tend to involve a mixture of languages during verbal communication. This contact may also result in the creation of slangs. These slangs are generally caused by urbanization, migrant labor and also industrialization as was witnessed in Indonesia.

Multilingualism practice generally develops cross-linguistic communication strategies like code switching and code mixing. When people switch from one language used at homes to the other outside the home environment, then codeswitching occurs. This is witnessed in countries like India where switching is witnessed between English, Hindu/Urdu, Bengali, and Tamil.

Multilingualism creates an aspect of diglossia whereby when there are two official languages, there is always one language that tends to dominate the other which is generally referred to as a subordinate. This happens when viewed from afunctional point. A glimpse of the diglossia situation in Africa indicates that English, French and Portuguese are characterized as high languages $(\mathrm{H})$ and the indigenous

Ones as low languages (L).

Multilingualism practice tends to create the development and general acquisition of cross-cultural communication skills. In this regard, people tend to learn different skills of the languages in place especially speaking, reading and even writing. These cross-cultural communication skills enable one to gain both the communicative and discourse competencies. Besides the linguistic consequences, there is also a political consequence that relies on the economic and political order of the society (Webb, 2000). This, in the long run, creates the majority and minority languages. Some of the majority languages become more powerful than others.

\section{The Benefits of Multilingualism}

It is estimated that over a billion people in the world speak more than one language fluently (Barasa, 2005). However, with the increased population of people in the world, the number of bilinguals may be currently twofold. This increased number of speakers is probably attributed to the regionalism and internationalism principles that are now embraced by many countries especially in the field of trade and commerce, innovation and also the technological advancements. These principles call for the speakers to be proficient in the working languages to effectuate communication.

The paper considers discussing the benefits of practicing multilingualism in the education sector not only in the formal education in learning institutions alone but also informal circumstances probably at homes. Therefore, some significant benefits of multilingualism in education whether formal or informal include the following:

Knowledge of more than two languages allows us to communicate with many people 
in both personal and professional contexts. This is because the vast amount of knowledge that people possess is often only effectively accessible through particular languages (Webb, 2000) whether official or unofficial. However, the unofficial languages that in most African contexts are generally regarded as native tend to be a viable medium for effective and clear presentation of knowledge that we possess. This is manifested in proven situations whereby knowing an indigenous language is believed to provide access to a vast reservoir of wisdom, expertise, knowledge, and skills contained in the bodies of speakers of the languages

concerned (Webb, 2000). Therefore multilingualism is a significant resource (Webb, 2000). When one knows the official language and perfectly speaks the indigenous languages, then the person will be able to synthesize knowledge and express it accordingly. It is, therefore, necessary to include indigenous languages in education to realize the benefits of synthesizing and clearly expressing knowledge.

Other scholars like (Bolinger, 1981) argue that anybody who knows only one language is generally not different from an animal that is restricted in communication. Thus a monolingual can best be described as a restricted animal with a barrier in communication referred to as 'fixity of reference' (Bolinger, 1981). This means that animals have messages connected with just one thing in the real world like a growl to an enemy, a particular scent to an attraction to mate and a cluck to a summon to abroad of ducks (Bolinger, 1981). Speaking one language can also be equated to a holophrastic stage of language development (Lyons, 1981). This means that a monolingual can be regarded as one who is still in the process of language acquisition and development and should learn other languages to effectuate multicommunication. Thus multilingualism opens doors forquick and easy communication. To remove the notion of 'fixity of reference,' entrenching multilingualism in education will, of course, enable one to avoid restrictions in communication thus enabling him to move to another stage of communication.

Multilingualism practices enhance intellectual flexibility and creativity. Recent studies have indicated that children who grow up in a supportive environment speaking more than one language from an early age are more perceptive and intellectually flexible than those who speak one language (King, 2007) By using the 'double first language acquisition' model as indicated by (King, 2007), children with parents regularly speaking different languages grow up being equally fluent and comfortable with the two home languages and can even learn a third and fourth language. Though this research focused on the home contexts, this is also practical in classroom contexts whereby students who are exposed to many languages will tend to be intellectually flexible. 


\section{Conclusion}

When foreign and indigenous languages are included in the multilingualism practices in education, then we should always try to avoid imposing these languages to the people. A keen measure and clear framework should be taken into account because imposing languages to people are dangerous and may cause tensions amongst different ethnic and or speech communities (Bolinger, 1981). Furthermore, as you impose a lingua franca and or foreign languages to people without also developing the indigenous languages, then this may lead to language death. There are more than 3,000 languages spoken in the world today that are at the point of dying, and some are already extinct (Opala, 2002).

Causes of language death may include among others the following factors: the imposition of languages on the others, language colonialism, foreign language dictatorship and assimilation of languages (Ochieng, 2002).

Other ways of language death include crude suppression of native languages as was the practice by the colonizing states. In a nutshell, depending on the composition of the society, multilingualism practice in education should embrace the indigenous, national, official and foreign languages as equal partners in the language policy development and education. 


\section{References}

Barasa, S. N (2005). Linguistic Internationalism: A Step towards Harmonious World Relations? In Proceedings of 17th-18thMarch on Across Borders: Benefiting from Cultural Differences, DAAD Regional Office in Africa, Nairobi, 300-12, 2005.

Bolinger, D. A Sears. Aspects of Language, Harcourt Brace Javanovich, Inc., New York, 1981

Bussmann, H. (1996). Rout ledge Dictionary of Language and linguistics, Rout ledge,

London, 1996.

King, A. (2007). Speaking in Tongues. In Reader's Digest, Readers Digest Association, Inc., USA, 96-101, 2007.

Lyons, J. (1981). Language and Linguistics: An Introduction,Cambridge University Press, Cambridge, 1981

Ochieng, P. (2002). The Dictatorship of English. In Daily Nation, Wednesday, March 6th, Nation Media Group, Nairobi, 11, 2002.

Opala, K. How Kenya Stands to Lose More than 10 Tribes. In Daily Nation, Wednesday, March 6th, Nation Media Group, Nairobi, 11, 2002

Webb, V. Kembo Sure. (2000). African Voices: An Introduction to the Languages and Linguistics of Africa, Oxford University Press, Southern Africa, 2000 